\section{A STUDY OF TREATIMENT MODALITIES IN THE MANAGEMENT OF LIVER ABSCESS: A SINGLE CENTRE OBSERVATIONAL STUDY}

KEY WORDS: Amoebic abscess, Pyogenic abscess Liver abscess, Percutaneous aspiration, pigtail catheter

\section{Dr Sunay Gandhi* Dr Shrikrishna Parab}

\section{Dr Ushma Butala}

Dr Smruti Ghetla
Resident doctor Department of General Surgery, H. B. T. Medical College \& Dr. R.N. Cooper Municipal Hospital,Vile parle. *Corresponding Author

Resident doctor Department of General Surgery, H. B.T. Medical College \& Dr. R.N.Cooper Municipal Hospital,Vile parle.

Assistant Professor, Department of General Surgery, H. B. T. Medical College \&Dr.R.N. Cooper Municipal Hospital, Vile parle.

Professor \& Head of Department, Department of General Surgery, H. B. T. Medical College \& Dr.R.N.Cooper Municipal Hospital,Vile parle.

Background: Liver abscess both amoebic \& pyogenic to be an important cause of morbidity \& mortality in tropical country. Treatment of liver abscess are medical management, percutaneous needle aspiration , percutaneous catheter drainage, surgical drainage. Liver abscess are space occupying lesion in liver. The aim of study is various treatment modalities of management of liver abscess.

Mehods: This is an observationa study for presentation of liver abscess and its management done in the department of general surgery H.B.T. Medical college \& Dr. R.N. Cooper Hospital, Mumbai over period of $1 \&$ half year. 78 cases of liver abscess were studied. Complete clinical examination \& investigation done..The associated morbidity \& mortality of all patients were reviewed.

Results: . In this study, 78patients (72 males and 6 females; age range, 18-72 years; average age, 45 years) with liver abscesses underwent either percutaneous needle aspiration, percutaneous catheter drainage, or surgical intervention along with appropriate antimicrobial therapy. Pyogenic liver abscess was more common than amoebic liver abscess Conclusions: In our experience of managing liver abscess, pyogenic liver abscess involving right lobe of the liver was common with the presentation of upper abdominal pain, high grade fever with chills and tender hepatomegaly. Ultrasound abdomen is very useful investigative tool in diagnosis and also in intervention and in the follow up of the condition and to evaluate progression or resolution Alcoholism becomes the most frequently associated risk factor. Medical management is the mainstay of the therapy, with percutaneous drainage methods reserved for very large abscesses or those with complications. There has been drastically reduction in complications and mortality with modern antiamoebic drugs, and percutaneous interventions. Still laparotomy is occasionally required for generalised rupture or patient not responding to Percutaneous intervention methods

\section{INTRODUCTION}

Amoebic and pyogenic liver abscesses are among the important causes of morbidity and mortality in tropical countries lihe India. Liver abscess was described early in 460-377 B. C. by Hippocrates, still it remains a challenging situation especially in tropical countries due to poor hygiene \& sanitation, alcoholism and reduced literacy rate due to its highly variable presentation, causing diagnostic difficulties. Due to the rising incidence in alcoholism, diabetics \& immunocompromised status, liver abscess becomes a matter of grave concern as complications rate are high especially in this sub- group, leading to increased morbidity and mortality.The advances in radiology like ultrasonography and CT with interventional techniques has of radiological guided aspiration and drainage of most of the liver abscesses.

\section{METHODS:}

The Present study was conducted in H.B.T. Medical college \& Dr. R.N. Cooper Hospital Mumbai during the period from June 2019 to March 2022. All 78 patients with the diagnosis of liver abscess were included in the study.The patients will be evaluated and followed up according to protocol. Detailed history of patient taken. Complete haemogram, LFT, Prothrombin time, Serology for amoebic antigen will be sent immediately on presentation. Ultrasound of Abdomen and Pelvis will be done routinely on the same day of presentation. Patient will be treated by medical/ image guided drainage/ surgical(open drainage) based on its site, size and other clinical parameters. Patient will be followed up daily clinically and LFT. USG Abdomen will be repeated on the $3^{\text {rd }}$ day if patient symptomatically not relieved. If the patient develops any of the complications like ruptured liver abscess into any of the serosal cavity, patient will be immediately take up for surgery.

\section{Inclusion Criteria}

- All cases of liver abscess diagnosed clinically and ultra sonographically.

- All cases of bacterial and parasitic liver abscess

- All cases in evolving, liquefied \& ruptured stage with or without peritonitis

Exclusion Criteria:

- Traumatic Liver Abscess

- Past history of liver

\section{RESULT:}

After reviewing the records of 78 patients with liver abscess analysis was done. Age distribution: Out of 78 patients 18 patients are more than 40 years. (77\% are young in the age group $20-40$ year). 4 out of 78 patients are females. Alcoholism is a major risk factor with 33 out of 74 male patients being alcoholics. 9 out of 78 patients had diabetes mellitus (DM), .6 patients were detected seropositive for Human Immunodeficiency virus out of 69 in whom testing was done.

\section{Symptom analysis}

\begin{tabular}{|l|l|l|}
\hline Symptoms Percentage & & No of patients \\
\hline Right hypochondriac pain & 78 & $100 \%$ \\
\hline Fever & 68 & $88 \%$ \\
\hline Jaundice & 6 & $8 \%$ \\
\hline Dysentery & 5 & $6 \%$ \\
\hline Vomiting & 9 & $12 \%$ \\
\hline Abdominal distension & 9 & $12 \%$ \\
\hline Respiratory symptoms & 9 & $12 \%$ \\
\hline
\end{tabular}

Mean Hemoglobin of patients was $11.6 \mathrm{gm} \%$.

- Analysis of complete leukocyte count 


\begin{tabular}{|l|l|l|}
\hline WBC Count & No of patients & Percentage \\
\hline Less than 5000 & 5 & $2 \%$ \\
\hline $5000-10000$ & 14 & $18 \%$ \\
\hline $10000-20000$ & 39 & $50 \%$ \\
\hline More than 20000 & 20 & $26 \%$ \\
\hline
\end{tabular}

\section{Analysis of liver function test}

- Albumin levels: Patients of amoebic liver abscess had low albumin level.

\begin{tabular}{|l|l|l|}
\hline Albumin level & No of patients & Percentage \\
\hline$<2 \mathrm{gm} \%$ & 3 & $4 \%$ \\
\hline $2-3 \mathrm{gm} \%$ & 53 & $68 \%$ \\
\hline$>\mathrm{gm} \%$ & 22 & $28 \%$ \\
\hline
\end{tabular}

Analysis of aspartate transaminase levels(SGOT)

\begin{tabular}{|l|l|l|}
\hline SGOT level & No of patients & Percentage \\
\hline Normal & 20 & $26 \%$ \\
\hline Mild elevation & 43 & $56 \%$ \\
\hline Moderate elevation & 15 & $18 \%$ \\
\hline
\end{tabular}

Mild elevation means the thrice the upper normal limit of SGOT level (<120 IU/dL) Analysis of alanine transaminase levels(SGPT)

\begin{tabular}{|l|l|l|}
\hline SGOT level & No of patients & Percentage \\
\hline Normal & 40 & $51 \%$ \\
\hline Mild elevation & 36 & $48 \%$ \\
\hline Moderate elevation & 2 & $1 \%$ \\
\hline
\end{tabular}

Mean alkaline phosphatases levels among 78 patients is $151.79 \mathrm{IU} / \mathrm{dL}$

Analysis of Bilirubin levels: Two patients had elevation in bilirubin but not detectable clinically. Two patients however had bilirubin raised with clinically detectable jaundice.

\begin{tabular}{|l|l|}
\hline & No of Patients \\
\hline Normal & 44 \\
\hline Raised dome of diaphragm & 25 \\
\hline Right pleural effusion & 13 \\
\hline Consolidation & 3 \\
\hline Left pleural effusion & 1 \\
\hline
\end{tabular}

Prothrombin time was deranged in 9 patients out of 78 . About 32 abscesses were central and 46 subcapsular in location with or without rupture. Subcapsular rupture was diagnosed in only one patient ultrasonography. Another case of subcapsular rupture was missed on USG that required computerised tomography to confirm the rupture which was done after patient did not respond to conservative line of management. Subdiaphragmatic rupture was diagnosed in 2 patients out of 78 patients on presentation. In one patient, the liver was reported normal with moderate free fluid in the abdomen. On paracentesis of the peritoneal cavity, purulent aspirate confirmed rupture of the abscess. Exploratory laparotomy revealed ruptured abscess from right lobe of liver. Abscess were partially liquefied in 59 cases, well liquefied in 8 cases, and unliquefied in 11 cases. One patient who on USG was having unliquefied abscess was diagnosed to have partial liquefied abscess on CT scan. Therapeutic role of ultrasonography: Percutaneous drainage was done in 38 out of 78 patients. Four patients were subjected for tapping of which two patients further required to be pigtailed as the abscess failed to resolve. In patients who were pigtailed, insitu duration of pigtail ranged from minimum of 3 to 22 days. Out of 36 patients who were pigtailed, about 5 patients developed bile leak. Mean duration of pigtail is 7 days. One patient required endoscopic biliary stenting as the biliary fistula did not resolve after 3 weeks of conservative treatment. ERCP revealed free leak of contrast from branch of right posterior hepatic duct. Patient responded with decrease in bile drainage from the pigtail in 4 days. Localised ruptures of the abscesses were treated conservatively With percutaneous drainage and medical management. 2 patients required laparotomy for generalisedp eritonitis, 1 due to generalised rupture and another following subdiap hragmatic rupture as patient did not respond to pigtailing. All patients received metronidazole along with a broad spectrum antibiotic. About 49 patients received a combination of cefoperazone and sulbactam while 19 received quinolones along with metronidazole. Chloroquine was given to all patients following metronidazole.

\section{DISCUSSION:}

In our study of 78 cases of liver abscess, the mean age group of the patient is 42.4 with the min age of 18 years to maximum of 75 years. The male to female ration in our study is 10:1 In the present study, Pyogenic liver abscess seen most commonly followed by Amoebic Liver Abscess, with more common in right lobe of the liver $95 \%$. Majority of population in present study was suffering from fever $(88 \%)$ at the time of presentation. In Our study all cases of pyogenic liver abscess were treated with percutaneous catheter drainage procedure and amoebic liver abscess were managed with antiamoebic drugs. In our study majority of the cases presented with pleuro pulmonary complications which includes pleural effusion in majority of the 14cases which resolved with medical therapy. In Our study, 2 patient presented with features of peritonitis due to ruptured liver abscess for which open surgical drainage was done.With the results in our study it can be safely said that the treatment of liver abscess can be according to the volume of the abscess cavity and response of the patient to antiamoebics. Small abscesses can be treated with antibiotics alone based on the local antibiotic policy, medium abscesses can be treated with aspiration and follow up for progression or resolution while percutaneous pigtail catheter drainage is a safe and effective mode of treatment for large liver abscesses.

\section{CONCLUSION :}

In our experience most common liver abscess presenting in our institution was pyogenic in nature involving right lobe of the liver was common with the presentation of upper abdominal pain, high grade fever with chills and tender hepatomegaly. . Most common age of presentation was 42.4 years. Alcoholism becomes the most frequently associated risk factor Ultrasound abdomen is very useful investigative tool in diagnosis and also in intervention and in the follow up of the condition and to evaluate progression or resolution. Thus it can be safely said that the treatment of liver abscess can be according to the volume of the abscess cavity and response of the patient to antibiotics and antiamoebics. Small abscesses can be treated with antibiotics alone based on the local antibiotic policy, medium abscesses can be treated with aspiration and follow up for progression or resolution while percutaneous pigtail catheter drainage is a safe and effective mode of treatment for large liver abscesses..

\section{REFERENCES}

1. Principles of Internal Medicine - Harrison's 16th edition pg. no. 752, Infectious diseases, Liver abscess.

2. Oshsner A.Pyogenic abscess of liver. Am J Surg 1938;40:292

3. McFadzean AJS, Chang KPS, Wong CC. Solitary pyogenic abscess of liver treated by closed aspiration and antibiotics: $A$ repoprt of 14 consecutive cases and recovery. BrJ Surg 1953;41:141-152

4. Maingoat's abdominal operations 9th edition volume 2, Seymour I. Schwartz and Harold ellis pg.no. 1215 Section XI , Liver, Pyogenic \& Amoebic abscesses.

5. Blumgart - Surgery of the Liver, Biliary Tract and Pancreas 4th Edition Vol.2 Pg.no. 928 Liver \& Biliary Infection \& Infestation, Pyogenic Liver Abscess, R.W.Strong.

6. Maingoat's abdominal operations 9th edition volume 2, Seymour I Schwartz and Harold ellis pg.no. 1218 Section XI , Liver, Pyogenic \& Amoebic abscesses.

7. Manual of Clinical problems in infectious disease 4th edition, Lippincott Williams \&Wilkins, pg.no.78,79

8. Maingoat's abdominal operations 9th edition volume 2, Seymour I. Schwartz and Harold ellis pg.no. 1218 Section XI, Liver, Pyogenic \& Amoebic

9. Maingoat's abdominal operations 9th edition volume 2, Seymour I. Schwartz and Harold ellis pg.no. 1216-1220 Section XI , Liver, Pyogenic \& Amoebic abscesses.

10. Sabiston Textbook Of Surgery Pg. no. 1487,1488,1494 Infectious Diseases, Pyogenic Liver Abscess. 